\title{
Distribution and Ecological Risk Assessment of Heavy Metals in Sediments in Chinese Collapsed Lakes
}

\author{
Yukui Li', Fei Liu ${ }^{1 *}$, Xiujie Zhou${ }^{1}$, Xin Wang ${ }^{1}$, Qingchuan Liu ${ }^{2}$, \\ Pengfei Zhu', Lichao Zhang ${ }^{1}$, Chongyu Sun ${ }^{1}$ \\ ${ }^{1}$ School of Environmental Sciences, Huaibei Normal University, Huaibei 235000, China \\ ${ }^{2}$ Hefei University of Technology, Hefei 230000, China
}

Received: 28 May 2016

Accepted: 26 July 2016

\begin{abstract}
Surficial sediments and water (27 samples each) were collected from three representative lakes collapsed by mining activities in Huaibei, China. Contents of heavy metals ( $\mathrm{Sb}, \mathrm{As}, \mathrm{Cd}, \mathrm{Pb}, \mathrm{Zn}$ ) in both water and sediments were detected via atomic absorption spectrophotometry and atomic fluorescence spectrometry, respectively. The variation coefficient $(C . V$. $)$ of each heavy metal as well as the partition coefficient $(K d)$ between surficial sediments and water was calculated. The ecological risks of heavy metals in collapsed lakes were assessed via geoaccumulation index $\left(I_{\text {geo }}\right)$, and we estimated the Pearson correlation coefficients between heavy metals. Together with the real situations around collapsed lakes, we resolved the sources of heavy metals. We found that the contents of heavy metals in water were basically below Surface Water Quality Standard I. The contents of heavy metals in the majority of sediment samples exceeded the background levels in the Yangtze River and Huai River areas, but were below the threshold effect concentration. The spatial distributions of heavy metals in surficial sediments were not uniform, as the C.V.s indicate medium variations. Analysis of Partition coefficient showed that Lieshan collapsed lake (LSH) was under severe risk. An analysis of $I_{g e o}$ revealed gentle-medium ecological risks from Sb, As, and Cd. The classification and frequency distributions of $I_{\text {geo }}$ of five heavy metals indicate that the ecological risk of Cd was the largest. The ecological risk was lowest in Yangzhuang collapsed lake (YZH). These results were confirmed by analysis of C.V. and Kd. Analysis of heavy metal sources showed that the inputs of Sb and As into the three collapsed lakes were human-driven and very complex, probably due to point-source pollution, including leaching from gangue piles and industrial discharge. Cd mainly originated from non-point-source agricultural pollution, while $\mathrm{Pb}$ and $\mathrm{Zn}$ might mainly originate from natural sources.
\end{abstract}

Keywords: heavy metal, sediment, collapsed lake, ecological risk, geoaccumulation index $\left(i_{\text {geo }}\right)$

*e-mail: liufei888@163.com 


\section{Introduction}

The extensive use of downhole coal mining in China has resulted in soil destruction, the formation of largearea mining-caused subsidence zones [1], and ponding and lake development in subsidence zones. These consequences have altered the ground ecoenvironment. The exploitation and use of coals is accompanied by the formation of abundant coal gangue and burnt waste, which are usually piled near or on the banks of subsidence lakes in mining areas. However, these wastes may damage the surrounding environment [2]. Six of the trace elements found in coals $(\mathrm{Hg}, \mathrm{As}, \mathrm{Se}, \mathrm{Pb}, \mathrm{Cr}, \mathrm{Cd})$ are considered to be the most noteworthy environmentally sensitive elements [3]. Se, $\mathrm{Pb}, \mathrm{Zn}, \mathrm{Cd}$, and $\mathrm{Sb}$ are very toxic and readily available in the environment. Since heavy metals are chronically circulating between water and particles, heavy metal pollution is more severe than organic matter or microorganism pollution [4]. The existing relevant research is focused on heavy metals in surface water and shallow groundwater [5], but is rarely targeted at the sediments of subsidence lakes. According to the priority pollutant lists (heavy metals) in and outside China as well as the situations in Huaibei mining areas, we selected five heavy metals ( $\mathrm{Sb}, \mathrm{As}, \mathrm{Pb}, \mathrm{Zn}$, and $\mathrm{Cd}$ ) that might be environmentally risky.

Heavy metal pollution is characterized by latency, wide source, non-degradability, and environmental accumulation [6], and heavy metals entering lakes are eventually deposited in lake sediments [7]. Once the water environment is changed, the heavy metals in the sediments would, through a series of physical, chemical, and biological processes, enter waters again [8]. Besides the heavy metal "source" and "sink" functions [9], the quality of lake sediment environment is closely associated with the well-being and sustainability of the whole aquatic ecosystem. Since the chemical behaviors and ecological effects of heavy metals in aquatic ecosystems are very complex, research about heavy metals in sediments has become a hotspot [10].

Existing research on the storage, conversion, and levels of heavy metals in sediments is focused on natural lakes, but rarely on mining-induced collapsed lakes. Especially in the arid and semi-arid areas of northern China, these artificial lakes would largely affect the local hydrology, climate, and living. Coal-producing areas were found with serious environmental degradation and pervasive gangue piling. Also, coal transportation and combustion causes modest pollution of water sediments. Thus, studying the distributions and ecological risks of heavy metals in collapsed lakes is very meaningful for reasonable water use in water-deficient areas.

The objective of the present study is to thoroughly uncover the distribution law and ecological risk assessment of the selected heavy metals ( $\mathrm{Sb}, \mathrm{As}, \mathrm{Cd}, \mathrm{Pb}$, $\mathrm{Zn}$ ) in different collapsed lakes of Huaibei, and thereby to provide scientific exact evidences of controlling heavy metal contamination in mine sediments. We will investigate:
1. The variation coefficients of heavy metal concentrations in sediments of different collapsed lakes, and how different these are among the selected heavy metals.

2. What are the contents of sediment-borne heavy metals among three collapsed lakes, and what factors may impact the space distribution characteristics of the selected heavy metals in sediment?

\section{Materials and Methods}

\section{Study Area}

Huaibei coalfield, located in northern Anhui Province, is a major coal industrial base in eastern China. This area is rich in coal reserves under good layer deposit conditions. Over 60 years of cumulative exploitation, coal mining caused large areas of land subsidence. So far, there are some 38 collapsed lakes in Huaibei mining area, with a subsidence water area of $\sim 32.9 \mathrm{~km}^{2}$. These lakes pond throughout the year and are 2-3 $\mathrm{m}$ deep on average (greatest depth $10 \mathrm{~m}$ ). The large-area collapsed lakes have changed the morphology in Huaibei. These artificial lakes are very different from some natural lakes, thus analyzing and monitoring the contents/distributions of sedimentborne heavy metals in these lakes would facilitate the reasonable utilization of collapsed lakes and provide scientific reference for treatment and research of heavy metal pollution in coal mining areas.

\section{Sample Collection and Processing}

We selected three representative collapsed lakes in Huaibei mining area: Xiangcheng $(\mathrm{XCH})$, Yangzhuang (YZH), and Lieshan (LSH). From each lake we set three sampling sites - to the eastern, middle, and western parts. In total, we distributed nine sampling points in each lake (Fig. 1) and samples were collected in August 2015. All sampling points were positioned using GPS. In total, 27 samples below a water depth of $50 \mathrm{~cm}$ were collected and put into 5-L polyethylene bottles until used. In addition, 27 samples ( $\sim 1 \mathrm{~kg}$ each) of surficial sediments were acquired and stored in a refrigerator. After the water samples were transported to the laboratory, $250 \mathrm{ml}$ of water were separated from each sample immediately and $\mathrm{HNO}_{3}$ was added until $\mathrm{pH}$ was $<2$. The samples were filtered through $0.45-\mu \mathrm{m}$ membranes and stored at $4^{\circ} \mathrm{C}$. In the laboratory, the sediment samples were put in a freeze-drying box, impurities were removed, they were ground with a mortar, passed through a 100-mesh sieve, stored in polyethylene bottles, sealed with polyethylene bags, and stored in a freezer until used.

\section{Element Analysis}

The samples were digested and instrumentally analyzed as per U.S. Environmental Protection Agency (EPA) methods. Specifically, $0.2500 \mathrm{~g}$ from each sediment 


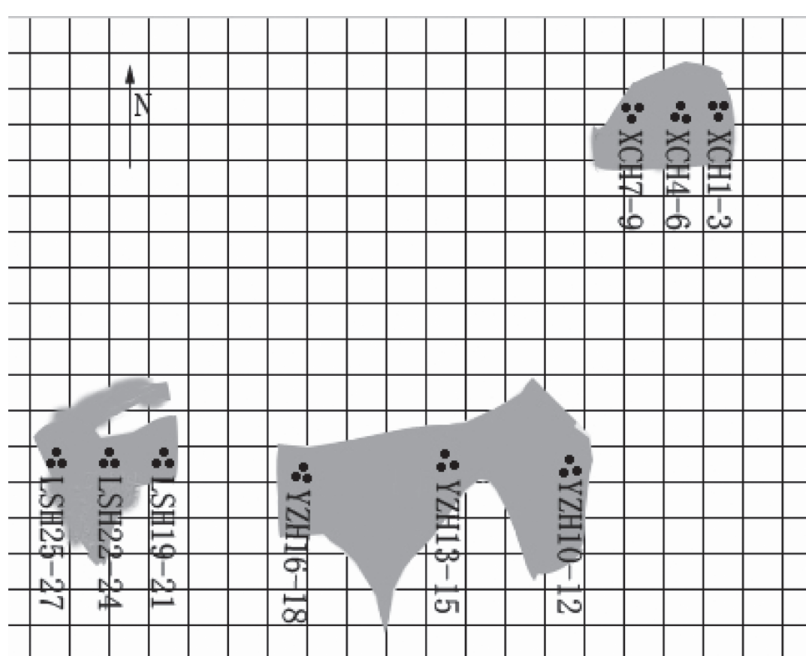

Fig. 1. Sampling sites in each collapsed lake.

sample was accurately weighed and put into a microwave digestion tank to which were added $4 \mathrm{~mL}$ of $\mathrm{HNO}_{3}, 5 \mathrm{~mL}$ of HF, and $2 \mathrm{~mL}$ of perchloric acid, successively. Then the tank was put into a microwave digestion instrument, and after $30 \mathrm{~min}$ of pre-digestion at $50^{\circ} \mathrm{C}$ the substances were digested following a preset program. After that, when the temperature dropped to $40^{\circ} \mathrm{C}$, the tank was taken out and put on an electric heating plate, followed by $\sim 1$ $\mathrm{h}$ of acid removal at $180^{\circ} \mathrm{C}$. After that, the digestion tank was cleaned with ultra-pure water several times each with little water. Then the sample was completely removed to a sample bottle, which was diluted with deionized water to $20 \mathrm{~mL} . \mathrm{Pb}, \mathrm{CD}$, and $\mathrm{Zn}$ were measured using an AAS-210 atomic absorption spectrophotometer (Beijing Beifenruili Instrument Co., Ltd, China), and $\mathrm{Sb}$ and As were detected via an AFS-2002 hydride generation-atomic fluorescence spectrometer (HGAFS, Beijing Jinsuokun Technology Developing Co., Ltd, China). The spiked recovery rate was $94.1-105.2 \%$.

\section{Heavy Metal Pollution Assessment}

So far, the single-factor index and Nemerow index are commonly used to assess heavy-metal pollution in soil or sediments. These two indices are capable of comprehensive assessment, but unable to determine the artificial pollution of heavy metals during supergene. This problem can be resolved using the geoaccumulation index $\left(I_{g e o}\right)$, which makes up for the shortcomings of other indices. Since the 1960s, $I_{\text {geo }}$ (also called Müller index) has been the most widely used index to quantify heavy metal pollution in sediments and other substances. It is expressed as follows:

$$
I_{\text {geo }}=\log _{2} \frac{C_{n}}{1.5 \times B_{n}}
$$

...where $C_{n}$ is the content of an element in sediments, $B_{n}$ is the chemical background value of this element in sediments, and 1.5 is the coefficient considering the variation of background values due to regional differences in rocks and is used to characterize the geological and sedimentary effects.

\section{Results and Discussion}

\section{Distribution of Heavy Metals in Overlying Water and Sediments}

Table 1 lists the content ranges of five heavy metals in the overlying water and sediments of the three collapsedlakes, as well as a comparison with surface water quality standards and background levels. Clearly, the contents of all five heavy metals in overlying water of all three collapsed lakes are below Water Quality Standard $\mathrm{I}$, except that the maximum $\mathrm{Sb}$ content is $4.26 \mu \mathrm{g} / \mathrm{L}$ and should be paid great attention. Moreover, the contents of all heavy metals (except $\mathrm{Zn}$ ) in surficial sediments at all sampling points are above the background levels in the Yangtze and Huai river areas to different degrees (Table 1). The background values of $\mathrm{As}, \mathrm{Pb}, \mathrm{Cd}$, and $\mathrm{Zn}$ are based on projects that are a geochemical survey of the YangtzeHuaihe River basin of Anhui province, including 663 sediment samples from nine lakes. But these monitoring data were not published. The background values of $\mathrm{Sb}$ in soil samples from Huaibei coal mines was $4 \mathrm{mg} \cdot \mathrm{kg}^{-1}[12]$. In particular, average $\mathrm{Sb}$ content is $6.67 \mathrm{mg} / \mathrm{kg}$, and average $\mathrm{As}, \mathrm{Pb}$, and $\mathrm{Cd}$ contents are $25.71,0.26$, and $74.83 \mathrm{mg} / \mathrm{kg}$, respectively, which are 2.92-, 1.08-, and 1.6-fold above the standards, respectively. Compared with a threshold effect concentration (TEC) [13-14], only As content is above the standard and 2.6-fold of TEC. A comparison shows that $\mathrm{Sb}, \mathrm{As}, \mathrm{Pb}$, and $\mathrm{Cd}$ in all three collapsed lakes will cause potential ecological hazards.

Coefficient of variation (C.V.) reflects the dispersity of data among different sampling points. Generally, C.V. $<10 \%, 10-100 \%$, and $>100 \%$ are considered weak, medium, and severe variability, respectively [15]. A larger environmental $C V$ of an element indicates more interference from artificial factors [16]. As for heavy metals in overlying water, the C.V.s of all elements are very large as "medium variation." The C.V.s of four heavy metals exceed 0.50 and C.V. of $\mathrm{Sb}$ is up to 0.86 . The minimum C.V. is 0.47 from As. The C.V.s in the overlying water change as $\mathrm{Sb}>\mathrm{Pb}>\mathrm{Cd}>\mathrm{Zn}>$ As.

The C.V.s of all heavy metals in sediments belong to medium variation. The C.V.s of $\mathrm{Sb}$ and As are larger (0.49 and 0.63 , respectively). The C.V.s of five heavy metals change in order to $\mathrm{As}>\mathrm{Sb}>\mathrm{Cd}>\mathrm{Zn}>\mathrm{Pb}$. Generally, the C.V.s of heavy metals are smaller in sediments versus overlying water, indicating that the overlying water is more vulnerable to the interference of human activities compared with sediments. The $\mathrm{Sb}$, As, and Cd in sediments are subjected to more human interference. The C.V. of As is significantly larger in overlying water versus sediments, indicating that 1) As in overlying water is under very severe human interference, and 2) the migration and conversion 
Table 1. Contents of heavy metals in water and sediments from three mining-related collapsed lakes in Huaibei.

\begin{tabular}{|c|c|c|c|c|c|}
\hline Element & $\mathrm{Sb}$ & As & $\mathrm{Pb}$ & $\mathrm{Cd}$ & $\mathrm{Zn}$ \\
\hline & \multicolumn{5}{|c|}{ Overlying water $(\mu \mathrm{g} / \mathrm{L})$} \\
\hline Minimum & 1.53 & 1.75 & 0.68 & N.D. & 3.6 \\
\hline Maximum & 4.26 & 15.8 & 4.7 & 0.14 & 36.5 \\
\hline Mean & 3.25 & 9.6 & 1.67 & 0.07 & 12.6 \\
\hline S.D. & 0.27 & 4.7 & 0.86 & 0.04 & 7.6 \\
\hline C.V. & $86.20 \%$ & $47.30 \%$ & $74.60 \%$ & $68.50 \%$ & $53.80 \%$ \\
\hline \multirow[t]{2}{*}{ EQS-SW } & 5 & 50 & 10 & 1 & 50 \\
\hline & \multicolumn{5}{|c|}{ Sediments (mg/kg) } \\
\hline Minimum & 1.79 & 3.8 & 21.78 & 0.08 & 48.43 \\
\hline Maximum & 11.64 & 37.43 & 48.65 & 3.47 & 127.59 \\
\hline Mean & 6.67 & 25.71 & 31.26 & 0.26 & 74.83 \\
\hline S.D. & 1.32 & 6.27 & 7.54 & 0.07 & 43.25 \\
\hline C.V. & $49.75 \%$ & $63.37 \%$ & $24.81 \%$ & $48.66 \%$ & $36.27 \%$ \\
\hline TEC & - & 9.79 & 35.8 & 0.99 & 121 \\
\hline Background level & - & 8.8 & 29 & 0.162 & 83 \\
\hline Fold above background level & - & 2.92 & 1.08 & 1.60 & 0.90 \\
\hline
\end{tabular}

Note: EQS-SW: Environmental Quality Standard for Surface Water

of As between overlying water and sediments are very weak. Results of C.V.s indicate that human activities are dominant factors affecting the variation of heavy metals in the collapsed lakes of Huaibei mining areas.

As reported, the C.V.s of $\mathrm{Zn}, \mathrm{Cd}$, and $\mathrm{Pb}$ in sediments from Dongdagou are very large, indicating the possible existence of point source pollution [17]. Sediments as an important indicator for water environment quality assessment have long been a focus [18-19]. Pollutants from multiple sources - including industry, agriculture, and transport - accumulate in sediments, then the continuous accumulation of toxic substances in sediments is extended through a series of exchange actions to the biological habitat areas, which via food chains will severely endanger the ecoenvironment and human health. Heavy metals, because of extensive sources, environmental accumulation, and persistent risks, become a major type of pollutant that largely affects sediment quality.

With chronic stability, heavy metals in sediments directly endanger the bottom-living organisms, and may be released to the overlying water where they would threaten the whole aquatic ecosystem [20]. The spatial distributions of five heavy metals in sediments of the three lakes are showed in Fig. 2. The distributive characteristics in the sediments of collapsed lakes are similar between $\mathrm{Sb}$ and As: $\mathrm{LSH}>\mathrm{XCH}>\mathrm{YZH}$. The distributive characteristics of $\mathrm{Pb}$ are $\mathrm{YZH}>\mathrm{XCH}>\mathrm{LSH}$. The distributive characteristics are similar between $\mathrm{Cd}$ and $\mathrm{Zn}: \mathrm{XCH}>\mathrm{LSH}>\mathrm{YZH}$.

The contents of sediment-borne heavy metals are different among the three collapsed lakes, which is due to the age of the lake formation and distance from coal piles. XSH and LSH are older and have stopped collapsing and become stable, while YZH is still young and unstable.

A coal gangue hill is located to the northeast of LSH. After soaking and leaching by rain, the heavy metals contained in the coal gangue will be gradually released to the environment, converge into lakes, and finally precipitate in sediments. Heavy metals in collapsed lakes may also originate from coal mining, washing, combustion and transport, which should be studied further.

$\mathrm{YZH}$ is a reserve water source for Huaibei City and basically is not threatened by any point source pollution. Thus, the heavy metal pollution in YZH is less severe than other two lakes. In comparison, $\mathrm{XCH}$ and $\mathrm{LSH}$ are near industrial areas, and received abundant industrial wastewater, which aggravated the heavy metal pollution in sediments.

\section{Partition Coefficient of Heavy Metals between Overlying Water and Sediments}

Partition coefficient is an important physiochemical parameter that portrays the behaviors of heavy metals in a water environment and reflects the migrating ability and potential ecohazard of pollutants between water-phase and solid-phase. Partition coefficient is the concentration ratio of a heavy metal in sediments relative to overlying water when the water-sediment two-phase system is balanced. Partition coefficient is expressed as: 

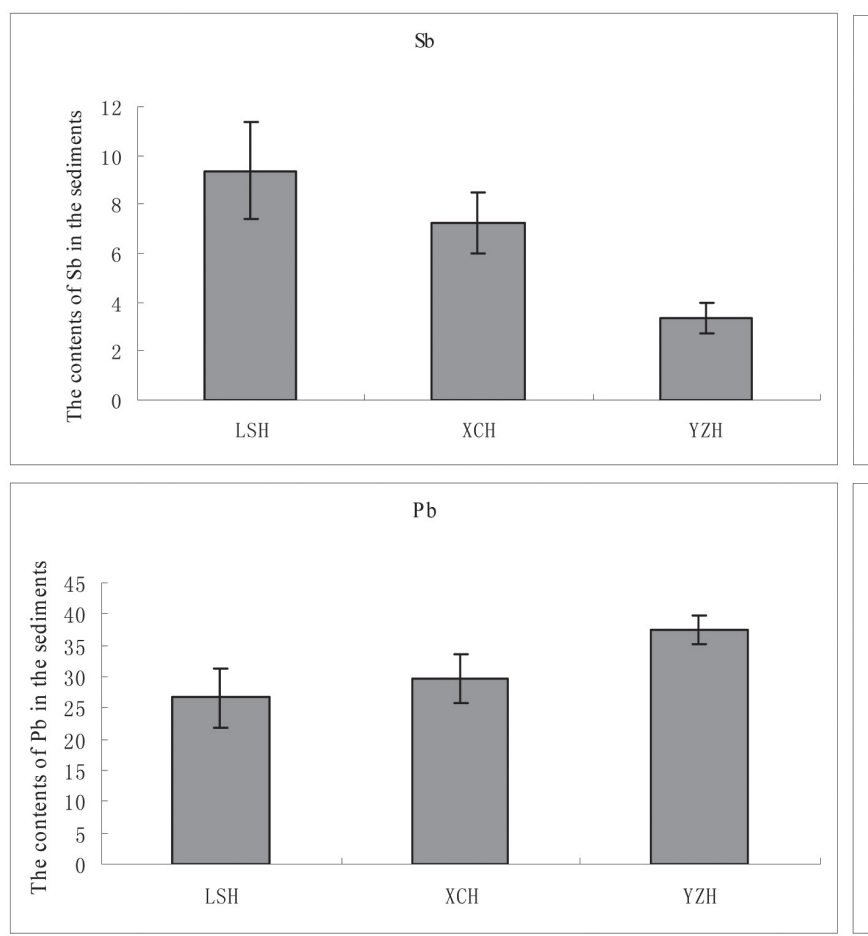

$\mathrm{Zn}$

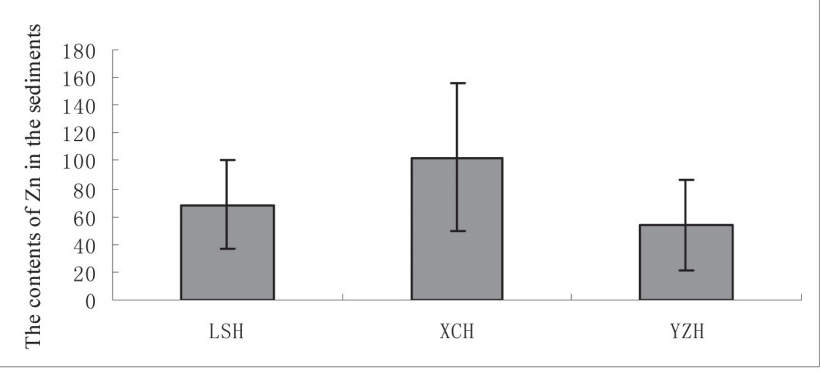

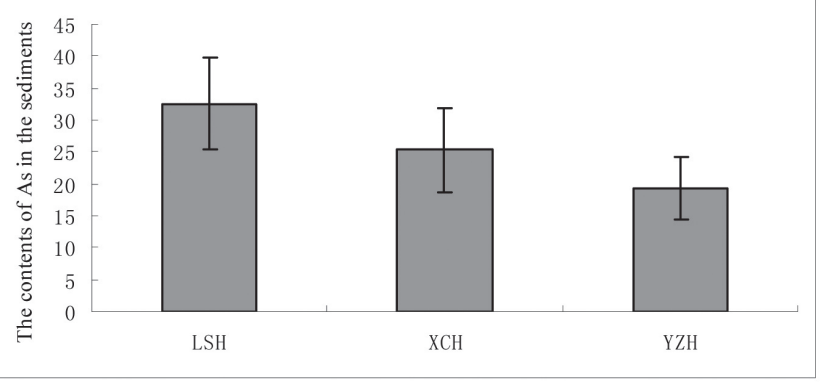

Cd

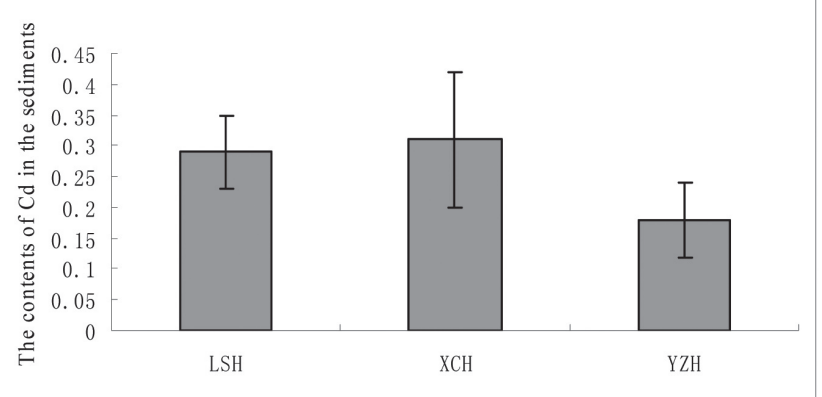

Fig. 2. Distributions of different heavy metals among three collapsed lakes.

$$
K_{d}=\mathrm{Cs} / \mathrm{Cw}
$$

...where $\mathrm{C}_{\mathrm{s}} /\left(\mathrm{mg} \cdot \mathrm{kg}^{-1}\right), \mathrm{C}_{\mathrm{w}} /\left(\mathrm{mg} \cdot \mathrm{L}^{-1}\right)$ are the contents of a heavy metal in sediments and overlying water, respectively, under a balanced system.

The means, ranges of partition coefficient, and number of samples listed in Table 2 were cited from the U.S. EPA
[21] (except for Sb data). Fig. 3 is a box plot of $K_{d}$ of heavy metals in sediments of three collapsed lakes. The upper, middle, and lower lines on the box represent the upper four percentile, median, and lower four percentile, respectively; the extended upper and lower edges represent $5^{\text {th }} / 95^{\text {th }}$ percentiles, respectively. Table 2 and Fig. 3 show the $K_{d}$ underlying heavy metals between

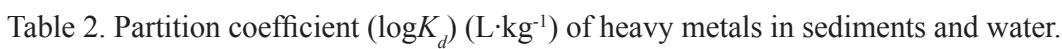

\begin{tabular}{|c|c|c|c|c|c|}
\hline & \multicolumn{5}{|c|}{$\log K_{d}$ of heavy metals in sediments and water $\left(\mathrm{L}^{\prime} \mathrm{kg}^{-1}\right)$} \\
\hline & $\mathrm{Sb}$ & $\mathrm{As}$ & $\mathrm{Pb}$ & $\mathrm{Cd}$ & $\mathrm{Zn}$ \\
\hline Mean & - & 2.5 & 5.1 & 3.6 & $3.7-$ \\
\hline Range & - & $1.6-4.3$ & $2.0-7.0$ & $0.5-7.3$ & $1.5-6.2$ \\
\hline Number of samples & - & 18 & 24 & 21 & 18 \\
\hline Study area (N=27) & $3.5-4.3$ & $3.4-4.5$ & $4.1-4.7$ & $2.3-2.9$ & $3.4-4.6$ \\
\hline LSH (N=9) & 3.7 & 3.79 & 4.22 & 2.42 & 3.63 \\
\hline XCH (N=9) & 3.73 & 3.8 & 4.25 & 2.62 & 3.86 \\
\hline YZH (N=9) & 3.98 & 3.9 & 4.33 & 2.64 & 3.79 \\
\hline
\end{tabular}



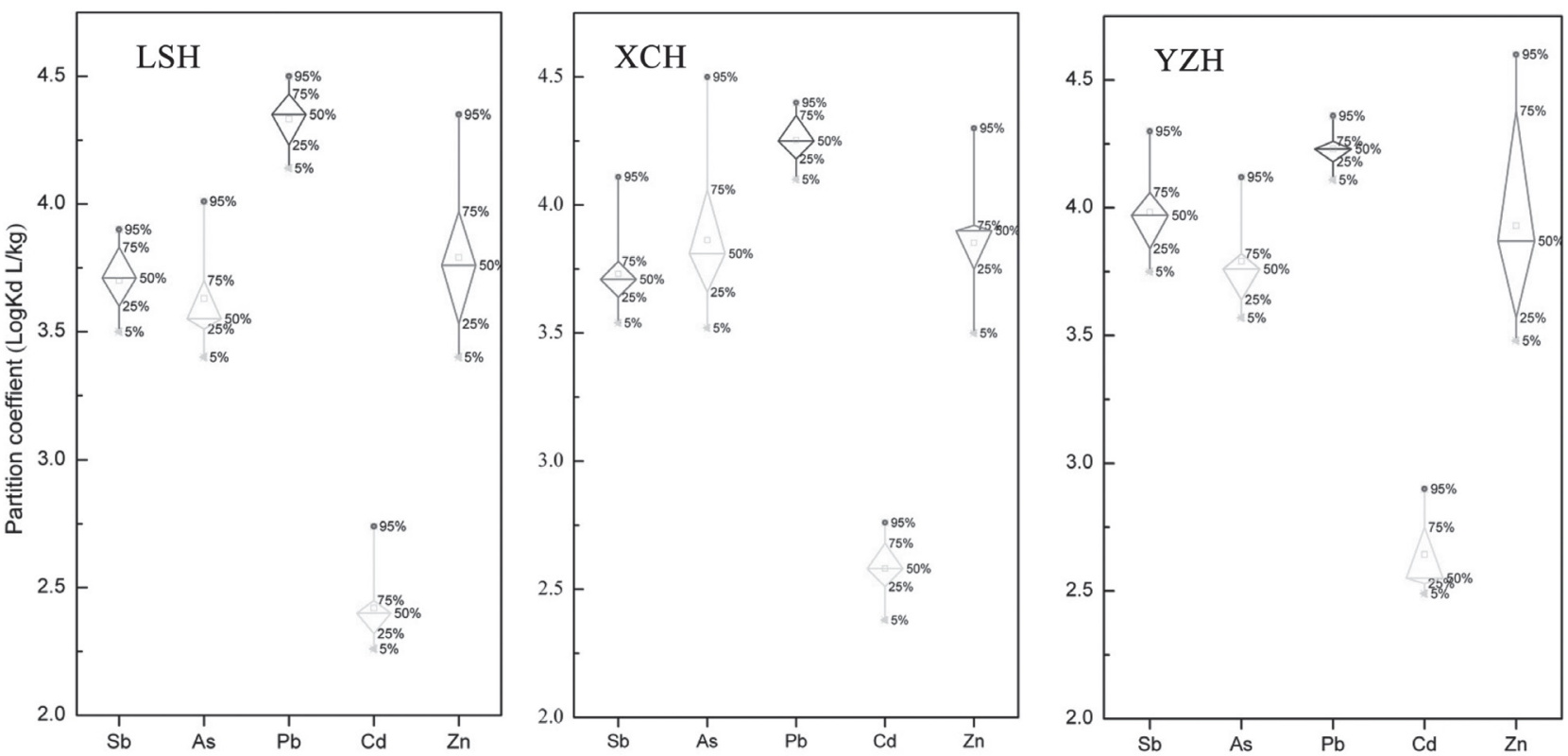

Fig. 3. Partition coefficient of heavy metals elements from collapsed lakes.

solid-water phases in collapsed lakes of Huaibei. Clearly, the $K_{d}$ in the water-sediment system are different among all elements, probably because of differences in chemical properties and adsorption characteristics among elements, which lead to the difference in two-phase partition among pollutants.

The $\log K_{d}$ of each heavy metal in LSH is significantly lower compared with other lakes (except $\mathrm{Pb}$ ), probably because the competitive adsorption drove the dissolution of heavy metals from sediments to the overlying water, thus raising the heavy metal contents in the overlying water, indicating that the ecological risk of LSH is relatively higher. $K_{d}$ of $\mathrm{Cd}$ is relatively lower among all heavy metals in three lakes, indicating that the ecological risk of $\mathrm{Cd}$ is very high.

As reported, metal concentrations are positively correlated with toxicity unit, and the strong acidic $\mathrm{pH}$ $(\mathrm{pH}<3.5)$ enhanced the metal toxicity by increasing metal activity and bioavailability [22]. Adsorption is a major route in which heavy metals are transferred from liquid phase to solid phase. The adsorption of heavy metals in sediments and suspended matter is driven by ion exchange, exclusive adsorption, nonexclusive adsorption, and complex adsorption. As reported, the chemical behaviors of heavy metals (As, $\mathrm{Cd}, \mathrm{Cr}, \mathrm{Cu}, \mathrm{Ni}$, $\mathrm{Pb}$, and $\mathrm{Zn}$ ) in the sediment-water interface are affected by environmental dredging, especially $\mathrm{Zn}$ and $\mathrm{Cd}$ (increasing rates $482.98 \%$ and $261.07 \%$, respectively), probably due to some characteristics of suspended particulate matter (SPM). [23].

\section{Geoaccumulation Index $\left(I_{\text {afo }}\right)$ of Heavy Metals in Collapsed Lakes}

As shown in Table 3, average $I_{\text {geo }}$ of Cd is 0.115 , while $2.3 \%, 4.7 \%, 12.3 \%$, and $32.6 \%$ of sampling points belong to severe, medium-severe, medium, and gentle-medium pollution, respectively; average $I_{\text {geo }}$ of As is 0.453 , while $43.7 \%$ and $18.6 \%$ of sampling points belong to abovegentle and medium pollution, respectively; average $I_{\text {geo }}$

Table 3. Classification and frequency-based distribution of heavy metal $I_{g e o}$ in three collapsed lakes.

\begin{tabular}{|c|c|c|c|c|c|c|c|}
\hline Class & $I_{\text {geo }}$ & Pollution degree & \multicolumn{5}{|c|}{ Pollution frequency (\%) } \\
\hline & & & $\mathrm{Sb}$ & $\mathrm{As}$ & $\mathrm{Pb}$ & $\mathrm{Cd}$ & $\mathrm{Zn}$ \\
\hline 0 & $\leq 0$ & No pollution & 63.7 & 56.3 & 91.6 & 48.1 & 84.7 \\
\hline 1 & $(0,1)$ & Weak-medium & 36.3 & 25.1 & 8.4 & 32.6 & 15.3 \\
\hline 2 & $(1,2)$ & Medium & 0 & 18.6 & 0 & 12.3 & 0 \\
\hline 3 & $(2,3)$ & Medium-severe & 0 & 0 & 0 & 4.7 & 0 \\
\hline 4 & $(3,4)$ & Severe & 0 & 0 & 0 & 2.3 & 0 \\
\hline 5 & $(4,5)$ & Severe-very severe & 0 & 0 & 0 & 0 & 0 \\
\hline 6 & $(5,10)$ & Very severe & 0 & 0 & 0 & 0 & 0 \\
\hline
\end{tabular}


of $\mathrm{Sb}$ is 0.316 , while $36.3 \%$ of sampling points belong to gentle-medium pollution; average $I_{\text {geo }}$ of $\mathrm{Zn}$ is -0.734 , while $15.3 \%$ of sampling points belong to gentle-medium pollution; and average $I_{\text {geo }}$ of $\mathrm{Pb}$ is -0.477 , while $8.4 \%$ of sampling points belong to gentle-medium pollution.

According to $I_{g e o}$, the pollution degrees change in the order $\mathrm{Cd}>\mathrm{As}>\mathrm{Sb}>\mathrm{Zn}>\mathrm{Pb}$. Nearly half of sampling points were polluted by $\mathrm{Cd}$ and $\mathrm{As}$, showing very high ecological risks. About $36.3 \%$ of sampling points belong to gentle $\mathrm{Sb}$ pollution and above. These phenomena should hardly be ignored.

The average $I_{\text {geo }}$ changes among heavy metals as $\mathrm{As}>\mathrm{Sb}>\mathrm{Cd}>\mathrm{Pb}>\mathrm{Zn}$, indicating that $\mathrm{As}$ and $\mathrm{Sb}$ pollution is very severe. Together with Fig. 2, it it clear that $\mathrm{As}$ and $\mathrm{Sb}$ levels in sediments of LSH are very high and indicate very severe ecological risks.

\section{Analysis of Heavy Metal Pollution Sources}

Heavy metals mainly originate from natural sources (weathering erosion of soil, rocks) and anthropogenic sources (sewage discharge from human production and life, e.g., industrial water, agricultural water, and living water are discharged directly) [24]. The sources of heavy metals in sediments are correlated with the sedimentary parent materials of rocks and minerals, and also with the emissions from human production and life [25]. In a certain area, the heavy metals in sediments are relatively stable. Thus, studying the correlations among heavy metals in sediments helps to reveal whether the sources of heavy metals in sediments are the same. A higher correlation indicates more similarity.

The Pearson correlations among five heavy metals in each sampling point were computed on SPSS 17.0. Results show that in $\mathrm{LSH}, \mathrm{Sb}, \mathrm{As}$, and Cd are significantly correlated pairwise (all $\mathrm{P}<0.01$ ), but $\mathrm{Zn}$ is not significantly correlated with other heavy metals. In $\mathrm{XCH}, \mathrm{Sb}, \mathrm{As}$, and $\mathrm{Cd}$ are significantly correlated pairwise (all $\mathrm{P}<0.05$ ).

In aquatic environments, $\mathrm{Sb}$ and other compounds mainly originate from the wastewater discharge from diverse manufacturing industries [26], Cd generally is a mark of insecticide and fertilizer use from agricultural activities [27], while $\mathrm{Pb}$ indicates motor vehicle pollution [28]. Combining the C.V.s of heavy metals in sediments as well as the actual situations around collapsed lakes, we think that in $\mathrm{LSH}$ and $\mathrm{XCH}, \mathrm{Sb}$, As, and $\mathrm{Cd}$ come mainly from anthropogenic sources; $\mathrm{Sb}$ and As mainly originate from point sources including leaching from gangue piles and industrial discharge, while $\mathrm{Cd}$ mainly comes from non-point-source agricultural discharge. Correlation analysis can reveal the sources of the different heavy metals in sediments, and correlation coefficients are usually performed by SPSS statistical software. If there is a relationship between heavy metals, they may have similar sources and vice versa. In $\mathrm{YZH}, \mathrm{Pb}$ and $\mathrm{Zn}$ are not significantly correlated with other heavy metals, so $\mathrm{Pb}$ and $\mathrm{Zn}$ may come mainly from natural sources.

\section{Conclusions}

By analyzing the heavy metal contents in three collapsed lakes, we find the three collapsed lakes already suffered gentle heavy metal pollution, especially in LSH and $\mathrm{XCH}$. One possible reason is the relatively older ages of these two lakes. Analysis of partition coefficient shows that LSH is under a very severe ecohazard.

The spatial distributions of heavy metals in surficial sediments are not uniform, as the C.V.s indicate medium variations. Average C.V.s of $\mathrm{Sb}, \mathrm{As}, \mathrm{Pb}$, and $\mathrm{Cd}$ are all above the background levels, but below TEC (except As).

$I_{\text {geo }}$ is used to assess ecological risks of heavy metals in sediments. Results show that Sb, As, and Cd impose gentle-medium ecological risks. The classification and frequency distributions of $I_{\text {geo }}$ indicate that the largest ecological risk comes from $\mathrm{Cd}$. The $I_{\text {geo }}$ s and classification of five heavy metals in the three collapsed lakes show that ecological risk is lowest in YZH. These results were confirmed by $C$.V.s and $K_{d}$ s.

Analysis of heavy metal sources shows that the input of $\mathrm{Sb}$ and As into the three collapsed lakes was humandriven and very complex, probably due to point-source pollution, including leaching from gangue piles and industrial discharge. Cd mainly originated from nonpoint-source agricultural pollution, while $\mathrm{Pb}$ and $\mathrm{Zn}$ may mainly originate from natural sources.

\section{Acknowledgements}

This work was funded by the National Science Foundation of China (No. 41371444), the China Spark Program (2014GA710040), the government of Anhui Province (No. 1301ZC04064), and the Anhui Provincial Natural Science Project (Nos. KJ2013ZD07 and KJ2011Z325), plus the talent Cultivation Plan of Huaibei City (No. 20130306), and the Anhui Scientifical Research Innovation Team for Ecological Restoration and Utilization of the coal-mining subsidy.

\section{References}

1. LIU F., WANG X., ZHU PENG-FEI. Analysis of distribution and environmental assessment of antimony in collapsedlake waters of Huaibei mining areas. Journal of University of Science and Technology of China. 42 (1), 26, 2012.

2. KOLKER A. Minor element distribution in iron disulfides in coal: A geochemical review. International Journal of Coal Geology. 94 (3), 32, 2012.

3. SWAINE D.J. Why trace elements are important. Fuel Processing Technology. 65-66, 21, 2000.

4. WOOD J.M. Biological cycle for toxic elements in the environment. Science.183 (4129), 1049, 1974.

5. ISMAIL Z., SALIM K., OTHMAN S.Z., RAMLI A.H., SHIRAZI S.M., KARIM R., KHOO S.Y. Determining and comparing the levels of heavy metal concentrations in two selected urban river water. Measurement. 46 (10), 4135, 2013.

6. ZHU PENG-FEI, LIU F. Effects of long-term fertilization on 
bioavailability of heavy metals in Shajiang black soil. Pol. J. Environ. Stud. 24 (2), 863, 2015.

7. DAUVALTER V., ROGNERUD S. Heavy metal pollution in sediments of the Pasvik River drainage. Chemosphere. 42 (1), 9, 2001.

8. REZA R., SINGH G. Heavy metal contamination and its indexing approach for river water. International Journal of Environmental Science \& Technology. 7 (4), 785, 2010.

9. HOSSAIN M.A., ALI N.M., ISLAM M.S., HOSSAIN H.M.Z. Spatial distribution and source apportion ment of heavy metals in soils of Gebeng industrial city, Malaysia. Environmental Earth Sciences. 73 (1),115, 2015.

10. MILENKOVIC N., DAMJANOVIC M. RISTIC M. Study of Heavy metal pollution in sediments from the Iron Gate (Danube River), Serbia and Montenegro. Pol. J. Environ. Stud.14 (6), 781, 2005.

11. AUDRY S., SCHÄFER J., BLANC G., JOUANNEAU J.M.. Fifty-year sedimentary record of heavy metal pollution $(\mathrm{Cd}$, $\mathrm{Zn}, \mathrm{Cu}, \mathrm{Pb}$ ) in the Lot River reservoirs (France). Environ. Pollut. 132 (3), 413, 2004.

12. QI CUI-CUI, LIU GUI-JIAN, KANG Y., LAM P.K.S., CHOU CHEN-LIN. Assessment and distribution of antimony in soils around three coal mines, anhui, china. Journal of the Air \& Waste Management Association, 61 (8), 850, 2011.

13. LIU F., DENG DAO-GUI, YANG, W., SHAO YUAN-QI, ZHU PENG-FEI, JI L.Risk evaluation of heavy metals in the surface sediments of Chaohu Lake in China. Fresenius Environmental Bulletin. 22 (7), 1807, 2013.

14. MACDONALD D.D., INGERSOLL C.G., BERGER T.A. Development and evaluation of consensus-based sediment quality guidelines for freshwater ecosystems. Archives of environmental contamination and toxicology. 39 (1), 20, 2000.

15. BASTAMI K.D., BAGHERI H., KHEIRABADI V., ZAFERANI G.G., TEYMORI M.B., HAMZEHPOOR A., SOLTANIE F., HAGHPARAST S., HARAMIB S.R.M., GHORGHANI N.F., GANJI S.Distribution and ecological risk assessment of heavy metals in surface sediments along southeast coast of the Caspian Sea. Marine pollution bulletin. 81 (1), 262, 2014.

16. HUANG SHUN-SHENG, TU J., LIU HONG-YING, HUA M., LIAO QI-LIN, FENG JIN-SHUN, WENG ZHI-HUA, HUANG GUANG-MING. Multivariate analysis of trace element concentrations in atmospheric deposition in the Yangtze River Delta, East China. Atmos. Environ. 43 (36), 5781, 2009

17. JIA Y., FANG M., WU You-Jun, LIU H., MIAO Y., WANG Xue-Tong, LIN Wei-Xin,TONG X. Pollution characteristics and potential ecological risk of heavy metals in river sediments of Shanghai. China Environmental Science. 33 (1), 147, 2013.

18. MA ZONG-WEI, CHEN K., YUAN ZENG-WEI, BI J., HUANG L. Ecological risk assessment of heavy metals in surface sediments of six major Chinese freshwater lakes. Journal of environmental quality. 42 (2), 341, 2013.

19. YI YUJUN, YANG ZHI-FENG, ZHANG SHANG-HONG. Ecological risk assessment of heavy metals in sediment and human health risk assessment of heavy metals in fishes in the middle and lower reaches of the Yangtze River basin. Environ. Pollut. 159 (10), 2575, 2011.

20. SENER S., DAVRAZ A., KARAGÜZEL R. Assessment of trace metal contents in water and bottom sediments from Eğirdir Lake, Turkey. Environmental earth sciences. 71 (6), 2807, 2014.

21. ALLISON J.D., ALLISON T.L. Partition coefficients for metals in surface water, soil, and waste. U. S. Environmental Protection Agency Office of Research and Development. EPA/600/R-05/074,7, 2005.

22. LEE S.H., KIM I., KIM K.W., Lee B.T. Ecological assessment of coal mine and metal mine drainage in South Korea using Daphnia magna bioassay. SpringerPlus. 4 (1), $1,2015$.

23. LIU C., FAN CHENG-XIN, SHEN QIU-SHI, SHAO SHIGUANG, ZHANG L., ZHOU QI-LIN. Effects of riverine suspended particulate matter on post-dredging metal recontamination across the sediment - water interface. Chemosphere. 144, 2329, 2016.

24. FRIGNANI M., BELLUCCI L.G. Heavy metals in marine coastal sediments: Assessing sources, fluxes, history and trends. Anal. Chim. 94 (7-8), 479, 2004.

25. BRADY J.P., AYOKO G.A., MARTENS W. Goonetilleke, A.. Enrichment, distribution and sources of heavy metals in the sediments of Deception Bay, Queensland, Australia. Marine pollution bulletin. 81 (1), 248, 2014.

26. FILELLA M., NELSON BELZILE N., CHEN YU-WEI. Antimony in the environment: a review focused on natural waters: I. Occurrence. Earth-Science Reviews. 57 (1), 125, 2002.

27. GARCIA R., MAIZ I., MILLAN E. Heavy metal contamination analysis of roadsoils and grasses from Gipuzkoa (Spain). Environ. Technol. 17 (7),763, 1996.

28. FACCHINELLI A., SACCHI E., MALLEN L. Multivariate statistical and GIS-based approach to identify heavy metal sources in soils. Environ. Pollut. 114 (3), 313, 2001. 